Gut, 1986, 27, 1049-1053

\title{
Adenosine deaminase activity in the diagnosis of tuberculous peritonitis
}

\author{
J M MARTINEZ-VAZQUEZ, INMA OCAÑA, E RIBERA, ROSA M SEGURA, \\ AND C PASCUAL \\ From the Departments of Internal Medicine and Biochemistry, Ciudad Sanitaria Valle de Hebron, \\ Autonomous University of Barcelona, Barcelona, Spain
}

SUMmARY We studied the activity of adenosine deaminase in the peritoneal fluid of 66 patients who were divided into five groups according to causes of ascites as follows: tuberculous peritonitis (group I), septic peritonitis (group II), secondary to malignant tumours (group III), miscellaneous conditions (group IV), and control subjects of transudates (group V). In patients with tuberculous peritonitis the enzyme activity was significantly higher than for the rest of the groups $(p<0.001)$, and enzyme concentrations in all patients were well above the upper non-tuberculous value. Adenosine deaminase activity in the peritoneal fluid has proved to be a simple and reliable method for early diagnosis of tuberculous peritonitis.

Adenosine deaminase (EC 3.5.4.4) is an enzyme of the catabolism of purine bases, capable of catalysing the deamination of adenosine forming inosine in the process. ${ }^{1}$ Its principal biological activity is related to proliferation and differentiation of lymphocytes; the enzyme activity is greater in $T$ lymphocytes than in $\mathrm{B}$ cells, ${ }^{2-4}$ and it is also inversely proportional to the degree of $\mathrm{T}$ cell differentiation. ${ }^{56}$

In previous studies ${ }^{7-11}$ we confirmed the high sensitivity and specificity of adenosine deaminase test for early diagnosis of tuberculous pleuropericardial and meningeal effusions. The adenosine deaminase increase was attributed to the maturative stage and/or degree of stimulation of $\mathrm{T}$ lymphocytes as a response of cell mediated immunity to mycobacterial antigens.

This prospective report evaluates the adenosine deaminase test in patients with tuberculous peritonitis.

\section{Methods}

\section{PATIENTS}

We studied the activity of adenosine deaminase in the peritoneal fluid of 66 patients with ascites who

Address for correspondence: Professor Jose M. Martinez Vazquez, Universidad Autonoma de Barcelona, Facultad de Medicina. Ciudad Sanitaria Valle de Hebron, Paseo Valle de Hebron s/n, 08035 Barcelona, Spain.

Received for publication 10 January 1986. were included in a systematised prospective protocol. This protocol evaluated clinical data (medical history and physical examination), chest and abdominal roetgenograms, tuberculin test (5 IU of PPD-T), and results of a series of diagnostic procedures, such as: (1) chemistry profile of peritoneal fluid (protein, glucose, LDH, and amylase content, and adenosine deaminase activity); (2) qualitative and quantitative cytology of the ascitic fluid in regard to ratio of lymphocytes and polymorphonuclear leukocytes; (3) cultural identification of microorganisms from peritoneal fluid, sputum, gastric aspirate, biopsied tissue specimens (Ziehl-Neelsen stain, cultures in agar and Lowenstein-Jensen media, and in medium for anaerobic bacteria), and (4) histological examination of peritoneal tissue obtained by laparoscopy or laparotomy-pathologic confirmation was available in eight $(12 \%)$ cases.

Patients were grouped according to the final aetiological diagnosis of the peritoneal fluid, as follows:

Group I included 10 patients with tuberculous peritonitis confirmed by bacteriologic and/or histopathologic studies. In eight cases, $M$ tuberculosis was cultured from peritoneal fluid, and in three of them peritoneal or pleural biopsy revealed caseating granulomatous serositis. In the remaining two cases, bacteriological studies were negative, but histologic examination of peritoneal and pleural specimens showed characteristic lymphocytic exudates, that 
resolved after administration of tuberculostatic agents.

Group II consisted of eight cirrhotic patients with septic peritonitis resulting from infected ascites. Causative microorganisms identified by culture of the peritoneal fluid and/or blood culture were Escherichia coli in five cases, Proteus mirabilis in two cases, and Bacteroides fragilis in one case.

Group III included 17 patients with ascites as a manifestation of malignant tumours. In all cases cytologic examinations of the ascitic fluid disclosed malignant cells at least in three different consecutive samples. Furthermore, peritoneal biopsy revealed neoplastic infiltration in three cases. The primary tumour was found in the ovary in six cases, gastrointestinal tract in five cases, kidney in one case, breast in one case, and in the remaining four cases the primary site was unknown.

Group IV consisted of six patients with miscellaneous conditions, such as pancreatic ascites (three cases), Whipple's disease (one case), Meigs' syndrome (one case), and chylous ascites secondary to cirrhosis of the liver (one case).

Group V consisted of 25 patients with ascites (acelullar, biochemically proved transudate) secondary to liver cirrhosis (23 cases) or hypoproteinaemia (two cases). This group was considered the control group.

The determination of adenosine deaminase in the peritoneal fluid was carried out after the colorimetric method of Galanti and Giusti, ${ }^{12}$ which is based on the indirect measurement of the formation of $\mathrm{NH}_{3}$ produced when adenosine deaminase acts in excess of adenosine. The Mann-Whitney test was used to analyse the data for statistical significance.

\section{Results}

The median enzyme value was $108.5 \mathrm{U} / \mathrm{l}$ in group I (patients with tuberculosis), $1.7 \mathrm{U} / 1$ in group II (patients with infected ascites), $6.3 \mathrm{U} / 1$ in group III (patients with neoplasms), $6.9 \mathrm{U} / 1$ in group IV (patients with miscellaneous conditions), and 0.01 in group $\mathrm{V}$ (control subjects). Table 1 refers to adenosine deaminase activity in the different groups; individual results are given in the Figure.

In patients with tuberculous peritonitis the enzyme value was significantly higher than for the rest of. the groups $(p<0.001)$. In none of the patients with tuberculous ascites adenosine deaminase activity was found to be lower than the upper value in the non-tuberculous groups.

Excluding the group of patients with tuberculosis, adenosine deaminase concentrations were found to be significantly different between groups III and IV (malignant tumours and miscellaneous conditions), and groups II and V (infected ascites and transudates). There were no significant differences in

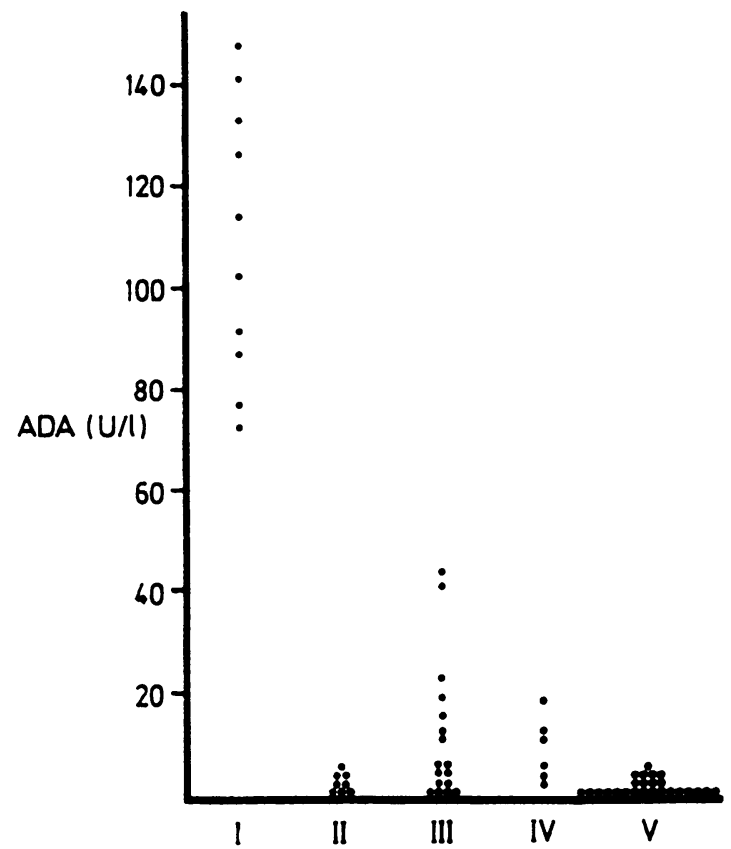

Figure Individual distribution of adenosine deaminase values in the different groups of peritoneal effusions: group I, tuberculous peritonitis; group II, non-tuberculous septic peritonitis; group III, neoplasms; group IV, miscellaneous, and group $V$, transudates or control subjects.

Table 1 Results of adenosine deaminase test in the peritoneal fluid (median values)

\begin{tabular}{lcccc}
\hline Group & Cases $(n)$ & $\begin{array}{l}\text { Adenosine } \\
\text { deaminase }\end{array}$ & Range & Significant difference \\
\hline I & 10 & $108 \cdot 5$ & $72 \cdot 5-148$ & II, III, IV, V $(\mathrm{p}<0 \cdot 001)$ \\
II & 8 & $1 \cdot 7$ & $0-6$ & I $(\mathrm{p}<0 \cdot 001)$, III $(\mathrm{p}<0 \cdot 05)$, IV $(\mathrm{p}<0 \cdot 01)$ \\
III & 17 & $6 \cdot 3$ & $0-44$ & I, V $(\mathrm{p}<0 \cdot 001)$, II $(\mathrm{p}<0 \cdot 05)$ \\
IV & 6 & 6.9 & $3-19$ & I, V $(\mathrm{p}<0 \cdot 001)$, II $(\mathrm{p}<0 \cdot 01)$ \\
V & 25 & $0 \cdot 01$ & $0-5$ & I, III, IV $(\mathrm{p}<0 \cdot 001)$ \\
\hline
\end{tabular}




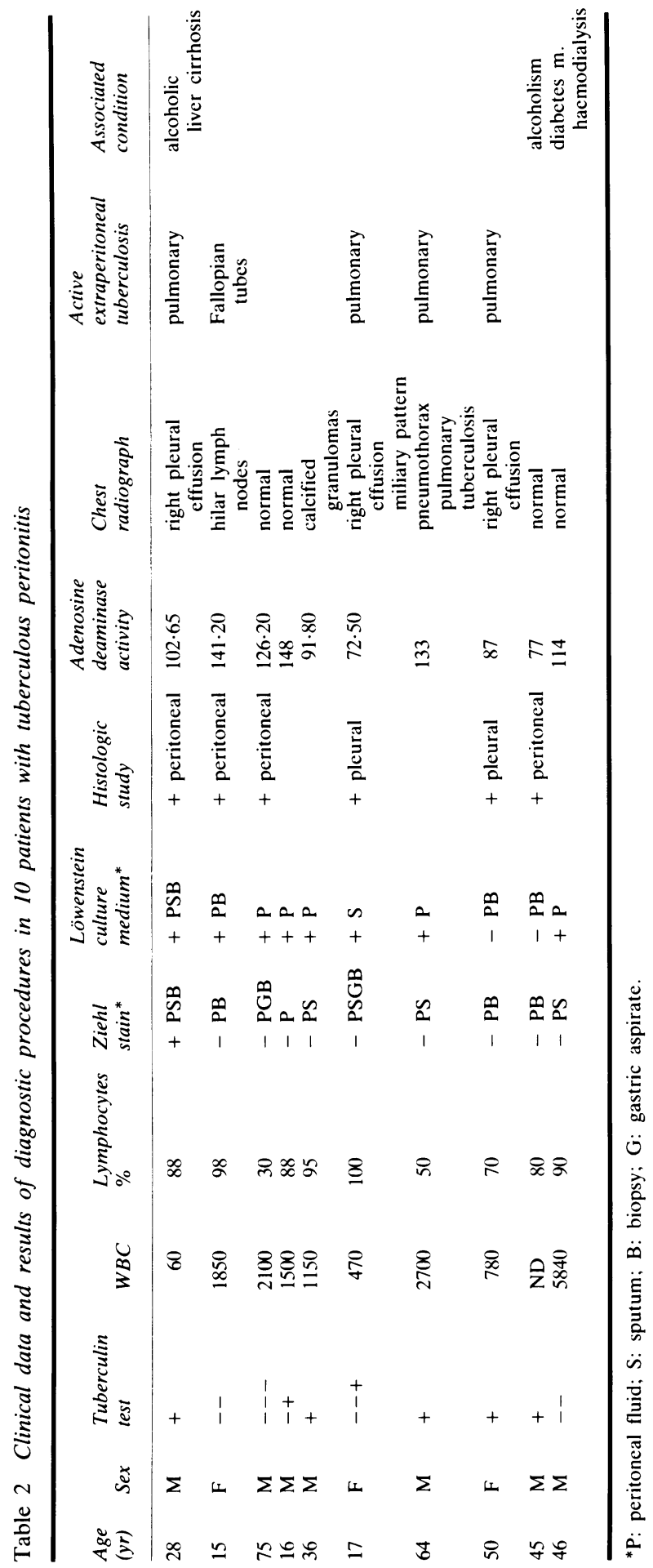


adenosine deaminase activity between the groups of patients with neoplasms and miscellaneous conditions, nor between patients with septic peritonitis and control subjects (transudate). Table 1 shows the significant differences between the groups.

Clinical data of the 10 patients with tuberculous peritonitis are summarised in Table 2 . The tuberculin test was positive (diameter of skin thickness $>10$ $\mathrm{mm}$ read 48 hours later) in seven $(70 \%)$ cases, increased proportion of lymphocytes (higher than $70 \%$ of the total cellularity) in eight $(80 \%)$ patients, and positive bacteriologic diagnosis also in eight $(80 \%)$ patients. The Ziehl-Neelsen stain was positive in only one case $(10 \%)$. Histological studies of peritoneal (four cases) and pleural biopsies (two cases) were always positive. Furthermore, adenosine deaminase test was more sensitive and specific than the absolute lymphocyte count; 10 of the 17 patients in group III (neoplastic ascites) had a higher number of lymphocytes than the lower limit of the tuberculous cases. The test was also more specific than lymphocytosis $(100 \%$ versus $70 \%)$.

There was no correlation between the adenosine deaminase concentration and the absolute lymphocyte count (Spearman's correlation coefficient).

\section{Discussion}

Despite a generalised impression that tuberculous peritonitis has become uncommon, this form of tuberculosis still occurs in endemic areas. Also, the prevalence of extrapulmonary tuberculosis is declining more slowly than the reduction in the number of cases of pulmonary tuberculosis. ${ }^{13}$ The incidence of tuberculous peritonitis in some large series of patients with tuberculous infection varies between $0.4 \%-0.7 \% ; ;^{14-18}$ it is about $4 \%$ in Spain. ${ }^{19}$

The diagnosis of tuberculous peritonitis is easy to establish whenever lymphocytic ascitic exudate occurs in a tuberculous patient with positive cultural identification of $M$ tuberculosis, but this occurs in $10 \%-40 \%$ of cases. ${ }^{17} 18{ }^{20}$ In most cases, diagnosis should be made by culture confirmation from ascitic effusion; Ziehl-Neelsen stained smears for standard microscopic detection of acid fast bacteria are not particularly useful. Culture confirmation is positive in only $8 \%-69 \%$ of the cases ${ }^{20}{ }^{21}$ although it may reach a positivity of $83 \%$ when a litre of fluid is used for bacteriologic diagnosis. Another problem is the time spent waiting for cultural proof of diagnosis (from 4-6 weeks).

Histologic examination plus cultural identification of $M$ tuberculosis from tissue biopsied under direct vision (laparoscopy) reaches a diagnostic sensitivity from $75 \%-100 \%{ }^{23-26}$ The procedure, however, may not be available at all medical institutions, and still has an extremely low mortality and morbidity in experienced hands.

The present results confirm the high sensitivity and specificity of adenosine deaminase test for early diagnosis of tuberculosis in cases of serous effusions. The selective enzyme increase in tuberculous peritonitis strongly supports the concept that the study of adenosine deaminase activity is of great value for identifying the tuberculous aetiology of ascites.

Liver disease and ascites are frequently seen in alcoholics, who also present with a high incidence of tuberculosis. Tuberculous peritonitis may be a transudate in up to $29 \%$ of the cases. ${ }^{27}$ For this reason the differential diagnosis of tuberculous peritonitis in alcoholics can be difficult to establish. In our series, two patients with tuberculous peritonitis were alcoholics; one of them had liver cirrhosis and ascites corresponding to a transudate. Increased adenosine deaminase activity was found in both cases, whereas in alcoholic patients with infected ascites (group II) and in alcoholics from the control group adenosine deaminase concentrations were lower. In our experience, the adenosine deaminase test proved to be useful in differentiating tuberculous and non-tuberculous ascites in alcoholic patients.

This specific serologic test provides a presumptive diagnosis of tuberculous peritonitis upon which to institute cheomotherapy, although it does not replace the standard histological and microbiological diagnostic methods.

\section{References}

1 Van Derr Weyden MB, Kelley WN. Human adenosine deaminase: distribution and properties. J Biol Chem 1976; 251: 5448-56.

2 Tung R, Silber R, Quagliata F, Conklyn M, Gottesman J, Hirschhorn R. Adenosine deaminase activity in chronic lymphocytic leukemia. Relationship to B- and T-cell subpopulations. J Clin Invest 1976; 57: 756-61.

3 Sullivan JL, Osborne WRA, Wedgwood RJ. Adenosine deaminase activity in lymphocytes. $\mathrm{Br} \mathrm{J}$ Haematol 1977; 37: 157-8.

4 Nishida Y, Okudaira K, Tanimoto K, Akaoka I. The differences in purine metabolism between $\mathrm{T}$ and $\mathrm{B}$ lymphocytes. Exp Hematol 1980; 8: 593-8.

5 Shore A, Dosch HM, Gelfand EW. Role of adenosine deaminase in the early stages of precursor $T$ cell maturation. Clin Exp Immunol 1981; 44: 152-5.

6 Barton R, Martiniuk F, Hirschhorn R, Goldschneider $\mathrm{I}$. The distribution of adenosine deaminase among lymphocyte populations in the rat. $J$ Immunol 1979; 122: 216-20.

7 Ocaña I, Martinez-Vazquez JM, Segura RM, Fernandez-de-Sevilla T, Capdevila JA. Adenosine deaminase in pleural fluids. Test for diagnosis of tuberculous pleural effusion. Chest 1983; 84: 51-3. 
8 Martinez-Vazquez JM, Ocaña I, Ribera E et al. Diagnóstico temprano de la tuberculosis pleuroperitoneal mediante la determinación de adenosina deaminasa. Med Clin (Barc) 1984; 83: 578-80.

9 Ocaña I, Martinez-Vazquez JM, Ribera E, Segura RM, Pascual C. Adenosine deaminase activity in the differential diagnosis of lymphocytic pleural effusions of tuberculous, neoplastic and lymphomatous origin. Tubercle 1986; 67: 141-5.

10 Ribera E, Martinez-Vazquez JM, Ocaña I, Segura RM, Pascual C. Cerebrospinal fluid adenosine deaminase activity in the diagnosis and follow-up of tuberculous meningitis. Neurology (In press).

11 Martinez-Vazquez JM, Ribera E, Ocaña I, Segura RM, Serrat M, Sagristá J. Adenosine deaminase activity in tuberculous pericarditis. Thorax (in press).

12 Giusti G. Adenosine deaminase. In: Bergmeyer HV, ed. Methods of enzymatic analysis. New York: Academic Press, 1974: 1092-9.

13 Alvarez S, McCabe WR. Extrapulmonary tuberculosis revisted: a review of experience at Boston City and other hospitals. Medicine (Balt) 1984; 63: 25-55.

14 Olcott CT, Pacchione D. Tuberculous peritonitis. Am Rev Tuberc 1933; 28: 27-61.

15 Farer LS, Lowell AM, Meador MP. Extrapulmonary tuberculosis in the United States. Am J Epidemiol 1979; 109: 205-17.

$16 \mathrm{Kahrs} \mathrm{T}$. Tuberculous peritonitis: a follow-up study of 169 cases. Tubercle 1952; 33: 132-8.

17 Sochocky S. Tuberculous peritonitis: a review of 100 cases. Am Rev Respir Dis 1967; 95: 398-401.

18 Dineen P, Homan WP, Grafe WR. Tuberculous peritonitis: 43 years' experience in diagnosis and treatment. Ann Surg 1976; 184: 717-22.

19 Maradona Hidalgo JA, Alvarez Alvarez C, Fernandez Rippe ML, Suarez Garcia E. Perspectiva actual de la tuberculosis peritoneal. Estudio de 26 pacientes. Rev Clin Esp 1983; 170: 133-6.

20 Sherman S, Rohwedder JJ, Ravikrishnan KP, Weg JG. Tuberculous enteritis and peritonitis. Report of 36 general hospital cases. Arch Intern Med 1980; 140: 506-8.

21 Borhanmanesh F, Hekmat K, Vaezzadeh K, Rezai HR. Tuberculous peritonitis. Prospective study of 32 cases in Iran. Ann Intern Med 1972; 76: 567-72.

22 Sirgh MM, Bhargava AN, Jain KP. Tuberculous peritonitis. An evaluation of pathogenetic mechanisms, diagnostic procedures and therapeutic measures. $N$ Engl J Med 1969; 281: 1091-4.

23 Geake TM, Spitaels JM, Moshal MG, Simjee AE. Peritoneoscopy in the diagnosis of tuberculous peritonitis. Gastrointest Endosc 1981; 27: 66-8.

24 Gendron V, Aubry P, Peghini M. Les aspects actuels de la tuberculose peritoneale en Afrique: étude de 77 observations. Med Trop (Mars) 1982; 42: 307-14.

25 Rodriguez de Lope C, San Miguel Joglar G, Pons Romero F. Laparoscopic diagnosis of tuberculous ascites. Endoscopy 1982; 14: 178-9.

26 Jorge AD. Peritoneal tuberculosis. Endoscopy 1984; 16: $10-2$.

27 Burack WR, Hollister RM. Tuberculous peritonitis. A study of 47 proved cases encountered by a general medical unit in twenty-five years. Am J Med 1960; 28: 510-23. 